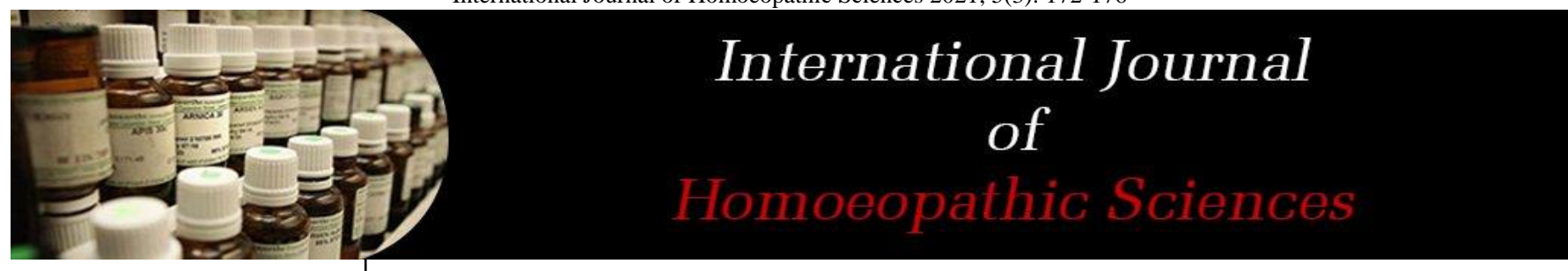

E-ISSN: $2616-4493$

P-ISSN: 2616-4485

www.homoeopathicjournal.com IJHS 2021; 5(3): 172-176

Received: 25-05-2021

Accepted: 27-06-2021

Dr. Vinitha ER

(1) MD [Hom], Research

Officer [H], S-1, Department

of Practice of Medicine,

National Homoeopathy

Research Institute in Mental

Health, Kottayam, Kerala,

India

(2) Under Central Council for

Research in Homoeopathy,

Ministry of AYUSH, Govt. of

India, New Delhi, India

Dr. Silpa K

(1) Junior Research Fellow,

National Homoeopathy

Research Institute in Mental

Health, Kottayam, Kerala,

India

(2) Under Central Council for Research in Homoeopathy, Ministry of AYUSH, Govt. of India, New Delhi, India

Corresponding Author: Dr. Vinitha ER (1) MD [Hom], Research Officer [H], S-1, Department of Practice of Medicine, National Homoeopathy Research Institute in Menta Health, Kottayam, Kerala, India

(2) Under Central Council for Research in Homoeopathy, Ministry of AYUSH, Govt. of India, New Delhi, India

\section{A case of urolithiasis impacted at vesico ureteric junction successfully treated with individualised homoeopathy}

\author{
Dr. Vinitha ER and Dr. Silpa K
}

DOI: https://doi.org/10.33545/26164485.2021.v5.i3c.422

\begin{abstract}
Urolithiasis refers to stones originating anywhere in the urinary system. Renal stones are of different types, the most common being the calcium oxalate stones. Various dietary, non-dietary, and urinary risk factors contribute to their formation. Non-contrast computed tomography is the preferred investigation for identification. This is a case report of $6 \mathrm{~mm}$ Renal calculi impacted at vesicoureteric junction causing hydroureteronephrosis. The patient had renal stone for six years and had undergone conventional treatment, but the response was unsatisfactory. After repertorisation, Homoeopathic medicine Lycopodium was prescribed in 200c potency and repeated at regular intervals. The impacted $6 \mathrm{~mm}$ renal calculi and Hydroureteronephrosis resolved within 48 days of treatment. The Urolithiasis symptom Score improved from 9 to 1 during treatment, and the MONARCH score of $+9 / 11$ shows a positive causal relationship between Lycopodium and the treatment outcome. The case report indicates the effectiveness of individualized Homoeopathic medicine in the management of impacted Urolithiasis.
\end{abstract}

Keywords: renal calculi, vesico-ureteric junction, hydroureteronephrosis, homoeopathy, Lycopodium clavatum

\section{Introduction}

They are mainly composed of calcium salts, uric acid, cysteine, and struvite. Calcium oxalate and calcium phosphate are the most common types accounting for greater than $80 \%$ of stones, followed by uric acid (8-10\%) and cysteine, struvite in remainders ${ }^{[1]}$. Renal stones can occur at any age; the peak incidence is between 20-49 years and increased risk in women than in men ${ }^{[2]}$.

The incidence of urolithiasis is increasing globally, with geographic, racial, and gender variation in its occurrence ${ }^{[3]}$. There found a shred of evidence that diminished fluid and calcium consumption, obesity, and weight gain are also contributing factors ${ }^{[4]}$. There are several theories as The matrix theory, The inhibitor theory, and The crystalloid theory for the formation of stones ${ }^{[5]}$. Food products such as coffee, tea, fruits, vegetables, and alcohol consumption were found as protective against stone disease. There is strong evidence that heredity is a chief contributor to the prevalence of nephrolithiasis ${ }^{[6]}$. In addition, there is a conclusion that global warming had a positive impact on the development of stones ${ }^{[7]}$.

Usually, urinary calculi lodge in one of the three sites of narrowing along the ureter: the pelvic-ureteric junction (PUJ), the vesicoureteric junction (VUJ), and in the mid-ureter at the impression of iliac vessels on ureters. The smaller the stone, the more distal it may lodge. Knowledge of the common sites of final stone impaction is crucial in diagnosis, treatment methods, and follow-up of the patients ${ }^{[8]}$. Forms of stones with increased risk were mould lithiasis, primary hyperoxaluria, cystinuria and infection, hypertension, and repeated surgery for urolithiasis ${ }^{[9]}$. The recurrence rate of urolithiasis is high, with $50 \%$ recurring within five years of the initial stone event ${ }^{[2]}$.

Unenhanced helical computed tomography is the best radiographic technique for diagnosing urolithiasis ${ }^{[10]}$. According to the modern system of medicine Renal stones of size 5-7 mm have a low-key chance $(50 \%)$ of passage, where those greater than $7 \mathrm{~mm}$ may need surgical intervention [11]. Open surgery for urolithiasis is put off by Extracorporeal Shock wave lithotripsy, ureteroscopy, and percutaneous nephrolithotomy ${ }^{[10]}$.

Homoeopathy is proved to be a boon where surgery is an adventure, such as aged ones, those suffering from other systemic diseases, and the economically weaker sections. 
Case reports are valuable observations in this field and they prospectively contribute towards undertaking similar studies in an adequate sample of patients.

\section{Methods}

Here is a case of VUJ Calculi treated with individualised Homoeopathy. Case reporting has done according to the HOM-CASE guidelines, an extension of CARE guidelines. ${ }^{[12]}$ CT (Computed Tomography) scan results revealed the presence of a $6 \mathrm{~mm}$ calculi, which resolved after treatment and evaluated through USG abdomen. The Urolithiasis symptom score at baseline and after treatment calculated. The causal relation between the Clinical improvement and the medicine prescribed assessed using the Monarch Inventory (Improved version of the modified Naranjo criteria for Homoeopathy)

\section{Case Summary}

A case of $6 \mathrm{~mm}$ Renal calculi impacted at VUJ causing hydroureteronephrosis, confer with acute exacerbation of pain in the left lower abdomen and lumbar region in the Outpatient Department of National Homoeopathy Research Institute in Mental Health Kottayam, on 6 May 2021. The patient had urolithiasis for six years and suffered from chronic low backache. He had stitching pain in the abdomen worse during the night, after eating, sitting, and driving for a long time. The patient was diagnosed as having Renal calculi six years back and on standard conventional medications with hydration and oral analgesics, but the response was unsatisfactory. The stitching pain in the lower abdomen, now exacerbated for one week and a CT scan revealed obstructing stone at the left VUJ with mild hydronephrosis in the left kidney. The right kidney was normal. On physical examination, tenderness was elicited on the left side of the abdomen and left flank region.

He was a healthy male with no relevant history of any diseases. He had a habit of taking protein powder for gymnastic purposes for a long time. His mother was hypertensive. There was no relevant family history of similar sufferings.

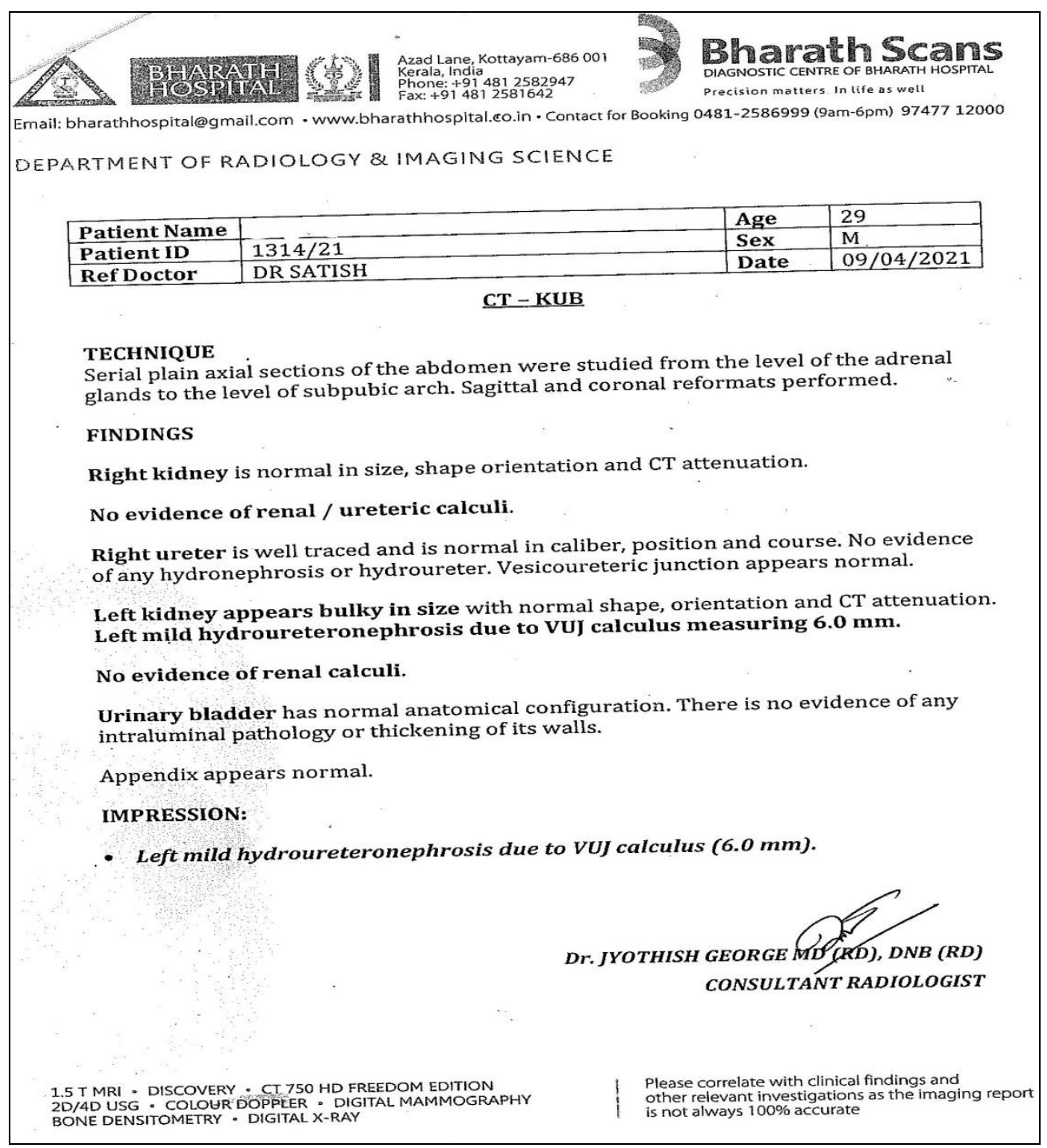

Fig 1: CT scan report showing $6 \mathrm{~mm}$ calculus at VUJ.

\section{Homoeopathic treatment, Follow-up, and Outcome Selection of medicine}

Homoeopathic case taking was done in detail. Selection of medicine based on the totality of symptoms of the patient as enlisted below:
- Workaholic nature

- Easily angered.

- Increased thirst

- Desire highly seasoned food

- Profuse sweat 
- Pain in the lower abdomen <night, after eating

- Backache in the lumbar region

- Headache < fasting.
Repertorization was done by Synthesis treasure edition 2009 v, in RADAROPUS software. ${ }^{(13)}$

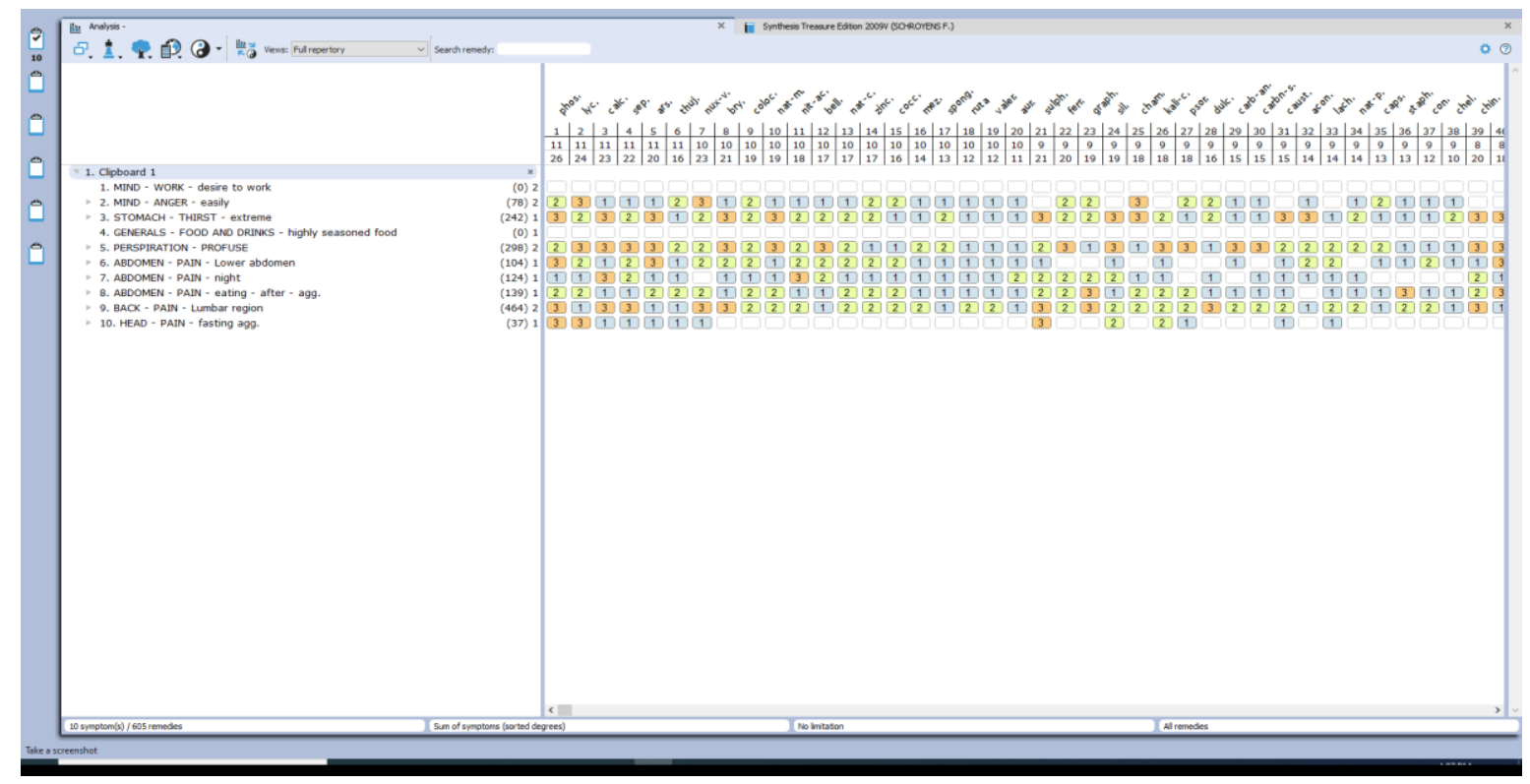

Fig 2: Repertorisation chart

The first four remedies on repertorisation were Phosphorus, Lycopodium clavatum, Calcarea carbonicum, and Sepia officinalis. The patient was thermally hot. So, the chilly remedy Phosphorus, which was of the highest rank in the repertorisation chart excluded. Lycopodium clavatum prescribed in 200 centesimal [C] potency based on the repertorial Totality. The medicine procured from The Kerala State Homoeopathic Cooperative Pharmacy LTD (Sponsored by Govt. of Kerala) GMP certified and dispensed from the pharmacy of
NHRIMH Kottayam.

\section{Prescription}

Lycopodium clavatum 200c was dispensed in Saccharum lactis to be taken on alternate days in early morning empty stomach. The patient was advised to take plenty of fluids and avoid foods such as spinach, chocolates, nuts, whole cereal flours, milk, etc

The case was followed-up for 2 months and the details are depicted in the following table

Table 1: Timeline of treatment

\begin{tabular}{|c|c|c|}
\hline $\begin{array}{c}\text { Date of visit } \\
\text { /follow up }\end{array}$ & Observations /symptoms and signs & $\begin{array}{c}\text { Prescribed medicine with } \\
\text { potency and doses }\end{array}$ \\
\hline 16.04 .2021 & $\begin{array}{c}\text { Pain on left lower abdomen and back with CT-KUB report confirming } \\
\text { presence of VUJ calculus }(6 \mathrm{~mm}) \text { with left mild hydronephrosis. } \\
\text { Recurrent attacks of headache <mental tension }\end{array}$ & $\begin{array}{c}\text { Lycopodium 200c } \\
\text { on alternate days, } \\
\text { for 2 weeks }\end{array}$ \\
\hline 30.04 .2021 & Pain in abdomen and headache reduced in intensity & $\begin{array}{c}\text { Lycopodium 200c once in } 3 \\
\text { days for 1 month }\end{array}$ \\
\hline 28.05 .2021 & $\begin{array}{c}\text { Abdominal pain much better, headache reduced, low backache persisting, } \\
\text { USG abdomen reveals no calculi/hydroureteronephrosis }\end{array}$ & $\begin{array}{c}\text { Lycopodium 200c } \\
\text { once a week for 1 month }\end{array}$ \\
\hline
\end{tabular}

\section{Result}

Homoeopathic medicine Lycopodium clavatum 200c was prescribed based on the repertorisation result obtained by bearing in mind the totality of symptoms of the patient and homoeopathic principles. There was a clinically relevant improvement for the abdominal pain from the first week of medication. The review USG after 48 days shows no impression of renal calculi or hydroureteronephrosis. The Urolithiasis symptom Score improved from 9 to 1 during treatment. MONARCH score of $+9 / 13$ indicates a positive causal relationship between the Homoeopathic medicine Lycopodium and expulsion of stone.

\section{Discussion}

In India, where homoeopathy is a national medical system, the market is growing at $25 \%$ a year, and more than 100 million people depend solely on this form of therapy for their health care, the acceptance of the dilute remedies shows no signs of abating ${ }^{[14]}$.

Homoeopathy is a distinct mode of therapeutics that offers curative treatment by gifting a good number of remedies that are helpful in not only removing the colic but also in preventing the reoccurrences with the help of constitutional, anti-miasmatic remedies, resulting in permanent cure of the condition ${ }^{[15]}$. By way of Spectrophotometric crystallization assay, there found a negative supersaturation of Calcium oxalate precipitation in presence of homoeopathic preparation of Berberis vulgaris ${ }^{[16]}$. On review of literature, a case report of a $16.9 \mathrm{~mm}$ stone located at VUJ after administration of Sarsaparilla 30C, passed through the urethra without causing any gross injury or haematuria, which was one among the marvellous cure through wholistic homoeopathy ${ }^{[17]}$.

In an observational study by Central Council for Research in 
Homoeopathy, the drugs which have been found useful in cases of Urolithiasis are Lycopodium clavatum, Sulphur, Nux vomica, Calcarea carbonicum, and Cantharis ${ }^{[18]}$. In a case study by Paul sumithran, multiple renal calculi of 4 years duration expelled with only two doses of Nitricum acidum 30 is explained ${ }^{[19]}$.

A case of VUJ Calculi treated with Individualized
Homoeopathy presented here. The patient presented with lower abdominal pain, backache, and pain in the lumbar region which got better even by the first dose of Lycopodium onwards. It took almost 48 days of Homoeopathic treatment to completely expel the stone from the urinary tract.

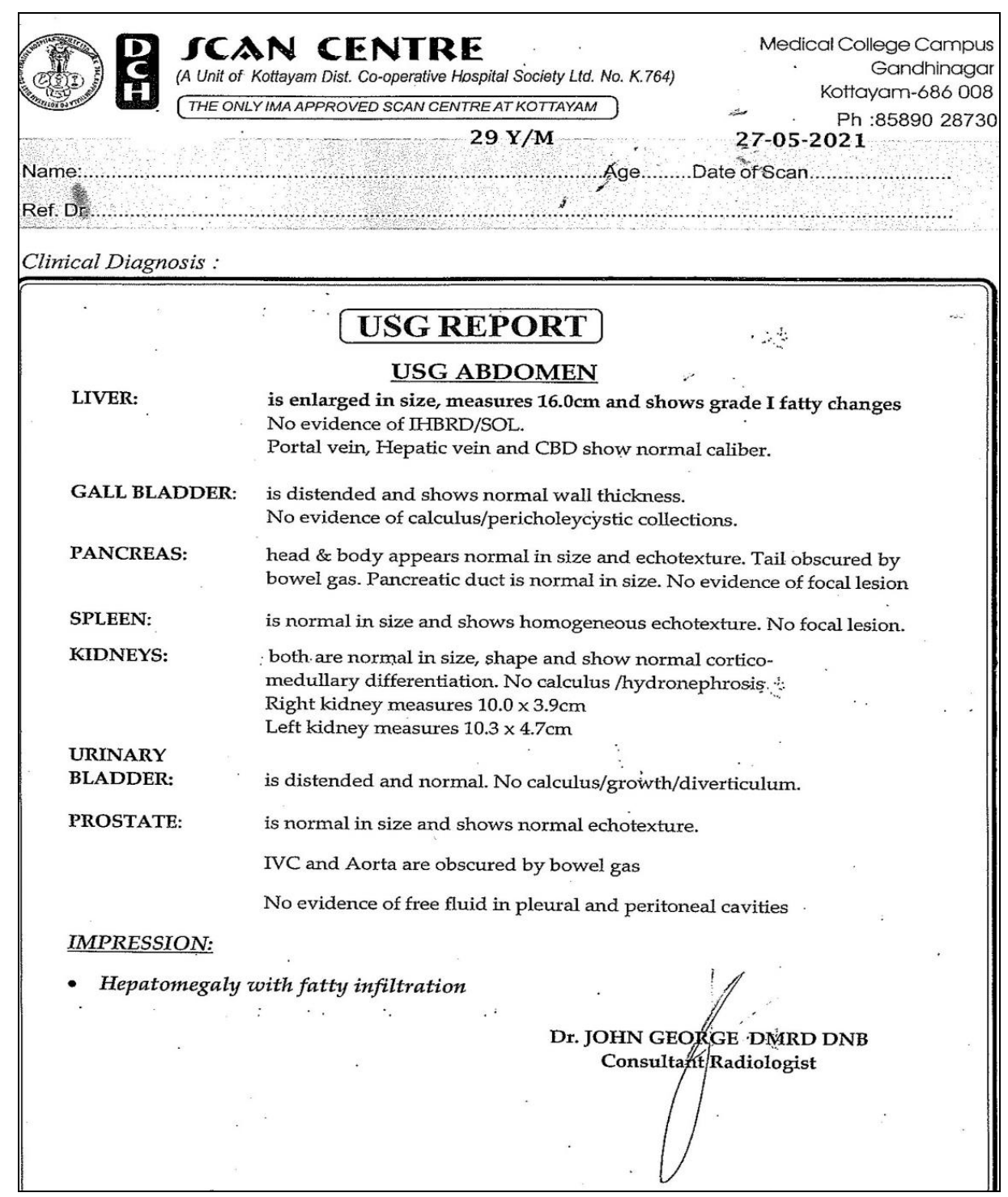

Fig 3: USG Report after 48 days of Homoeopathic treatment showing no renal calculi/hydroureteronephrosis.

The symptoms related to Urolithiasis were studied using Urolithiasis Symptom Score before and after treatment.

Table 2: Urolithiasis Symptom Score ${ }^{[18]}$

\begin{tabular}{|c|c|c|c|}
\hline Sl.no & Symptoms & Before treatment & After treatment \\
\hline 1 & Pain/colic & 3 & 1 \\
\hline 2 & Haematuria & 0 & 0 \\
\hline 3 & Dysuria & 0 & 0 \\
\hline 4 & Stone & 2 & 0 \\
\hline 5 & Size of stones & 3 & 0 \\
\hline 6 & Position of stone-kidney & 0 & 0 \\
\hline 7 & Position of stone-ureter & 1 & 0 \\
\hline 8 & Position of stone-bladder & 0 & 0 \\
\hline & Total score & 9 & 1 \\
\hline
\end{tabular}

Total scoring was done in 22. In which 1-7 are mild cases, 8-14 moderate and $15-22$ is severe. Here, with homoeopathic management, the score got reduced from 9 to
1. The MONARCH score of +9 indicates that the improvement attributed to the Homoeopathic medicine Lycopodium. 
Table 3: MONARCH Inventory ${ }^{(20)}$ (improved version of the Modified Naranjo criteria for Homoeopathy) Maximum possible score per case is +11

\begin{tabular}{|c|c|}
\hline Domain & Score \\
\hline Was there an improvement in the main symptom or condition for which the homeopathic medicine was prescribed? & +2 \\
\hline Did the clinical improvement occur within a plausible timeframe relative to the medicine intake? & +1 \\
\hline Was there a homeopathic aggravation of symptoms? & 0 \\
\hline $\begin{array}{c}\text { Did the effect encompass more than the main symptom or condition (i.e., were other symptoms, not related to the main } \\
\text { presenting complaint, improved or changed)? }\end{array}$ & +1 \\
\hline $\begin{array}{c}\text { Did overall well-being improve? } \\
\text { (Suggest using a validated scale or mention about changes in physical, emotional, and behavioural elements) }\end{array}$ & +1 \\
\hline $\begin{array}{c}\text { Did "old symptoms" (defined as non-seasonal and non-cyclical symptoms that were previously thought to have } \\
\text { resolved) reappear temporarily during the course of improvement? }\end{array}$ & 0 \\
\hline $\begin{array}{l}\text { Are there alternative causes (i.e., other than the medicine) that-with a high probability-could have produced the } \\
\text { improvement? (Consider known course of disease, other forms of treatment, and other clinically relevant }\end{array}$ & +1 \\
\hline Was the health improvement confirmed by any objective evidence? (e.g., investigations, clinical examination, etc.) & +2 \\
\hline Did repeat dosing, if conducted, create similar clinical improvement? & +1 \\
\hline Total Score & +9 \\
\hline
\end{tabular}

We should put forth evidence-based scientific homoeopathy to the world rather than empty, false claims that cause more harm to the profession. The main takeaway lesson from this case is to bring hope in the form of Homoeopathy for those economically weaker sections of our society who can't afford the expenses of surgery and postsurgical care or those who do not want to undergo the trauma of surgery and other conventional treatments.

\section{Conclusion}

The case of $6 \mathrm{~mm}$ Renal calculi impacted at VUJ with mild hydroureteronephrosis resolved within 48 days of Homoeopathic treatment. The present case report serves as a valuable clinical observation although conclusions cannot be drawn from isolated experiences.

\section{Conflict of Interest Statement}

The authors declare that there is no conflict of interest.

\section{Funding}

The authors received no financial support for the research, authorship and/or publication of this article.

\section{Informed consent}

Written informed consent was obtained from the patient prior to publication

\section{Reference}

1. Barnela SR, Soni SS, Saboo SS, Bhansali AS. Medical management of renal stone. Indian J Endocrinol Metab. 2012;16(2):236.

2. Aggarwal R, Srivastava A, Jain SK, Sud R, Singh R. Renal stone: a clinical review. EMJ Urol 2017;5(1):98103

3. Romero V, Akpinar H, Assimos DG. Kidney stones: a global picture of prevalence, incidence, and associated risk factors. Rev Urol 2010;12(2, 3):e86.

4. Taylor EN, Stampfer MJ, Curhan GC. Obesity, weight gain, and the risk of kidney stones. Jama. 2005;293(4):455-62.

5. Broadus AE, Thier SO. Metabolic basis of renal-stone disease. N Engl J Med 1979;300(15):839-45.

6. Goldfarb DS, Fischer ME, Keich Y, Goldberg J. A twin study of genetic and dietary influences on nephrolithiasis: a report from the Vietnam Era Twin (VET) Registry. Kidney Int 2005;67(3):1053-61.

7. Brikowski TH, Lotan Y, Pearle MS. Climate-related increase in the prevalence of urolithiasis in the United States. Proc Natl Acad Sci USA 2008;105(28):9841-6.

8. Saed MA, Shaban MM, Murshidi MM, Murshidi MM. Location of Ureteral Stones. Do They Lodge Where We Think They Do?.

9. Amato M, Lusini ML, Nelli F. Epidemiology of nephrolithiasis today. Urol Int. 2004;72(1):1-5.

10. Miller NL, Lingeman JE. Management of kidney stones. BMJ 2007;334(7591):468-72.

11. Zarse CA, McAteer JA, Sommer AJ, Kim SC, Hatt EK, Lingeman JE et al. Nondestructive analysis of urinary calculi using micro computed tomography. BMC Urol. 2004;4(1):1-8.

12. Van Haselen RA. Homeopathic clinical case reports: development of a supplement (HOM-CASE) to the CARE clinical case reporting guideline. Complement. Ther. Med 2016;25:78-85.

13. Schroyens F. synthesis Treasure edition 2009v. Radar Opus 2.2, 2019

14. Prasad R. Homoeopathy booming in India. Lancet. 2007;370(9600):1679-80.

15. Singh V. Renal Calculi and its Homoeopathic approach.

16. Ganesan T, Bhavani Ravi D, Vasavan J, Khurana A, Nayak D, Periandavan K. Homoeopathic preparation of Berberis vulgaris as an inhibitor of Calcium oxalate crystallization: An in vitro evidence. Ind $\mathrm{J}$ Res Homeopat 2015;9(3):152

17. Gupta AK, Gupta J, Siddiqui VA, Mishra A. A big urinary calculus expelled with homoeopathic medicine.

18. Siddiqui VA, Singh H, Gupta J, Nayak C, Singh V, Sinha MN et al. A multicentre observational study to ascertain the role of homoeopathic therapy in Urolithiasis.

19. Sumithran PP. A case of multiple urinary calculi.

20. Lamba CD, Gupta VK, van Haselen R, Rutten L, Mahajan N, Molla AM et al. Evaluation of the modified Naranjo criteria for assessing causal attribution of clinical outcome to homeopathic intervention as presented in case reports. Homeopathy 2020;109(04):191-7. 